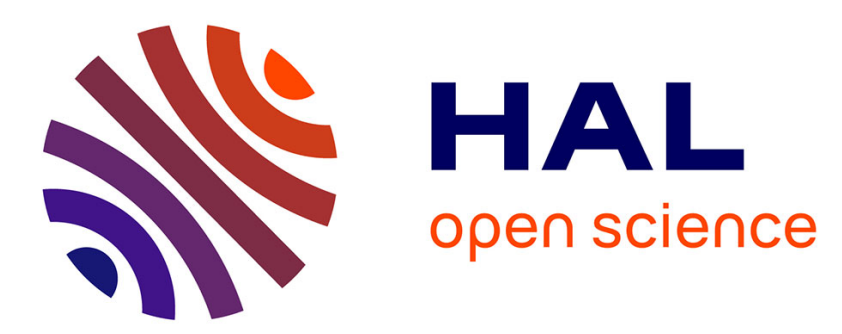

\title{
Nondestructive characterization of nanoporous alumina films using terahertz scattering imaging
} Min Zhai, Alexandre Locquet, Mi Jung, Deokha Woo, D.S. S Citrin

\section{To cite this version:}

Min Zhai, Alexandre Locquet, Mi Jung, Deokha Woo, D.S. S Citrin. Nondestructive characterization of nanoporous alumina films using terahertz scattering imaging. Surface and Coatings Technology, 2021, 408 (22), pp.126792. 10.1016/j.surfcoat.2020.126792 . hal-03120044

\section{HAL Id: hal-03120044 \\ https://hal.science/hal-03120044}

Submitted on 26 Nov 2021

HAL is a multi-disciplinary open access archive for the deposit and dissemination of scientific research documents, whether they are published or not. The documents may come from teaching and research institutions in France or abroad, or from public or private research centers.
L'archive ouverte pluridisciplinaire HAL, est destinée au dépôt et à la diffusion de documents scientifiques de niveau recherche, publiés ou non, émanant des établissements d'enseignement et de recherche français ou étrangers, des laboratoires publics ou privés. 
Nondestructive Characterization of Nanoporous Alumina Films Using Terahertz Scattering Imaging

\section{Min Zhai, ${ }^{1,2}$ A. Locquet, ${ }^{1,2}$ Mi Jung, ${ }^{3}$ Deokha Woo, ${ }^{4}$ and D. S. Citrin ${ }^{1,2 *}$}

1. Georgia Tech-CNRS UMI 2958, Georgia Tech Lorraine, 2 Rue Marconi, 57070 Metz, France

2. School of Electrical and Computer Engineering, Georgia Institute of Technology, Atlanta, Georgia 30332-0250 USA

3. Konkuk University Global Campus, 268 Chungcheonbuk-do, 27478 Republic of Korea

4. Sensor System Research Center, Korea Institute of Science and Technology, Seoul, Republic of Korea

*Corresponding: david.citrin@ece.gatech.edu 


\section{Abstract}

2

3 Ordered nanoporous (NP) alumina $\left(\mathrm{Al}_{2} \mathrm{O}_{3}\right)$ films were grown on $\mathrm{Al}$ substrates through

4 a two-step electrochemical anodization process. The morphology as well as the

5 roughness are characterized by terahertz $(\mathrm{THz})$ reflectometry and scattering imaging.

6 In particular, we show that before the second anodization, irregular surface morphology

7 of the $\mathrm{NP} \mathrm{Al}_{2} \mathrm{O}_{3}$ films leads to significant $\mathrm{THz}$ scattering, whereas the far more

8 homogeneous films following the second anodization show far less scattering. The

9 regularity of the surface morphology is not readily ascertained using visible-light

10 optical microscopy. The $\mathrm{THz}$ results are corroborated by field-emission scanning

11 electron microscopy (SEM) and atomic-force microscopy (AFM), both of which are

12 time consuming, not easy to operate, and can only provide local characterization of NP

$13 \mathrm{Al}_{2} \mathrm{O}_{3}$ films on $\mathrm{Al}$ substrate. might damage the films. THz-based techniques thus allow

14 for the rapid nondestructive characterization of the surface morphology of the entire

$15 \mathrm{NP} \mathrm{Al}_{2} \mathrm{O}_{3}$ films on the 10-100 $\mu$ m length scale, important for a range of applications,

16 while providing information over macroscopic scan areas, and obviate the need for

17 sample preparation required by other common surface-morphology characterization

18 techniques.

19 Keywords: Terahertz imaging, Nondestructive testing, Morphology, Nanoporous

20 alumina film, Characterization. 
Highlight:

- Terahertz scattering imaging has been applied 


\section{INTRODUCTION}

51 Due to their optical transparency [1-3], thermal stability [1], biocompatibility [4], as

52 well as the controllability of structural parameters [5], nanoporous (NP) alumina $\left(\mathrm{Al}_{2} \mathrm{O}_{3}\right)$

53 films have attracted scientific and technological attention for nanotechnology and 54 nanoengineering applications, such as drug delivery [4,6,7], electrochemical sensors $55[8,9]$, molecular transport [6,10,11], and solar-energy conversion [12]. Compared with 56 bulk crystal $\mathrm{Al}_{2} \mathrm{O}_{3}, \mathrm{NP} \mathrm{Al}_{2} \mathrm{O}_{3}$ has higher hardness, corrosion resistance, and wear resistance [13].

Anodization is an electrochemical process used to form an oxide layer on the surface of the native metal [13]. Recently, the most commonly used anodization method to form highly ordered $\mathrm{NP} \mathrm{Al}_{2} \mathrm{O}_{3}$ is a two-step process. Unlike the single anodization process, which may lead to nonuniform pores and interpore distances [14], a wellordered NP array may result after the two-step process because the purpose of the first anodization process is the formation of pattern for the second anodization. The parameters of $\mathrm{NP} \mathrm{Al}_{2} \mathrm{O}_{3}$, such as diameter and depth, are controlled by the applied voltage, the composition and concentration of electrolyte, as well as the duration and temperature of the anodization $[5,15]$.

To date, optical microscopy [16], scanning electron microscopy (SEM) [17-19], atomic force microscopy (AFM) [19,20], transmission electron microscopy (TEM) [19], infrared spectroscopy [21], and x-ray diffraction (XRD) [22] are the most common ways to characterize of $\mathrm{NP} \mathrm{Al}_{2} \mathrm{O}_{3}$. These techniques, however, have limitations for 71 characterizing $\mathrm{NP} \mathrm{Al}_{2} \mathrm{O}_{3}$ films. For example, limited magnification and the necessity of 72 continuous focusing adjustment resulting from the height variation of $\mathrm{NP}^{-1} \mathrm{Al}_{2} \mathrm{O}_{3}$ films, make optical microscopy problematic in some ways for morphology characterization 
problem can be to some extent mitigated, but at the cost of lower transverse resolution. Even though AFM can generate a three-dimensional image based on the surface morphology and height difference, it only provides surface, rather than depth, information. Moreover, because of the small scan image size and relatively long scan time, AFM fails to provide global and instant information with nano-scale lateral resolution. Infrared spectroscopy may be used for structural characterization of NP $\mathrm{Al}_{2} \mathrm{O}_{3}$ because of its ability to scan a relatively large area and provide fast inspection [23]. However, the approach presents several drawbacks, such as the potential of introducing damage into the $\mathrm{NP} \mathrm{Al}_{2} \mathrm{O}_{3}$ film owing to overheating, as well as the limitations on the depth information provided. Since SEM can observe both the surface and cross-sections, it is the most appropriate method for the systematic study of the microstructure of electrically conductive materials. To have a better brightness variation and enhance the conductivity for improving difficult focusing problems and image distortions, sputtering a conductive layer on the $\mathrm{Al}_{2} \mathrm{O}_{3}$ film, in some cases, is necessary. This limits resolution to sputtered conductive grain size and the reuse of samples for other tests. Even though TEM may provide surface and subsurface information, laborious sample preparation, excessive power of electrons, and strict sample requirements limit its widespread use, especially in industries. XRD is mainly a laboratory tool due to the ionizing nature of x-rays. Finally, optical microscopy may not provide the resolution on a sufficiently fine scale. A nondestructive, noncontact, and nonionizing approach possessing micron scale resolution is thus highly desirable. Terahertz (THz) electromagnetic waves, whose frequency range refers to $100 \mathrm{GHz}$ to $10 \mathrm{THz}$ range, can penetrate many electrically insulating materials that is opaque to visible and infrared light, and transparent to $\mathrm{x}$-rays. THz radiation presents no known health risks to biological tissue at the power levels utilized [24]. To date, THz-based 

$101[25,26]$, explosives [27,28], ancient paintings [29,30], automotive coatings [31],

techniques have been employed to characterize various materials, such as glass fibers polymers [32,33], and steel products [34,35]. A key point is that THz-based techniques provide the combined capability of giving depth and morphological information over the $10-100 \mu \mathrm{m}$ scale while enabling scanning over macroscopic areas, which are superior to both SEM and AFM approaches, that are limited to characterizing microscopic areas and require special training to instrumental operations as well as sample preparation.

In a previous work by the authors [16], $\mathrm{THz}$ birefringence of $\mathrm{NP} \mathrm{Al}_{2} \mathrm{O}_{3}$ films fabricated by a two-step electrochemical anodization process, was characterized nondestructively by polarization-resolved $\mathrm{THz}$ spectroscopy. Moreover, the film thickness was calculated based on THz results and showed an excellent agreement with the value measured by cross sectional field-emission scanning electron microscopy. In Ref. [36], the authors employ THz quantum cascade lasers to conduct spatially resolved spectral analysis of powdered samples. Inhomogeneity in constituent concentrations is mapped out by the scattered signal. Though the approach is termed "diffuse reflection imaging," no direct evidence of true diffusive nature is presented [37]. In the present study, THz reflective imaging and $\mathrm{THz}$ scattering imaging are employed to characterize the homogeneity of $\mathrm{NP} \mathrm{Al}_{2} \mathrm{O}_{3}$ films, which is poor following the first anodization, but markedly regular following the second anodization. (We make no claim anent the diffusive nature of the scattering.) This scattered signal is likely to be due to a rough surface morphology as well as of inhomogeneous structure in the film itself, though our measurement does not provide a distinction between these two effects. Instead, we focus on the approach as a rapid and nondestructive diagnostic. These results are 
124 corroborated by SEM and AFM. One area with rough surface morphology is observed

125 in THz scattering images, which is validated by SEM measurement.

126

127

128

\section{SAMPLE AND EXPERIMENT}

The fabrication of self-ordered $\mathrm{NP} \mathrm{Al}_{2} \mathrm{O}_{3}$ films on a grain-free aluminum foil (99.99\%, 100 um in thickness, Tokai Aluminum Foil Company) [38] is conducted by a typical electrochemical anodization process. The dimensions of the $\mathrm{Al}$ foil used in this research are $6.7 \mathrm{~cm}$ by $1.4 \mathrm{~cm}$. Pretreatment to degrease the foil and to remove initial surface oxide are first performed. To minimize surface roughness of the starting Al foil, substrates are first prepared by electropolishing for $60 \mathrm{~s}$ with a bias voltage of $20 \mathrm{~V}$ in a 1:4 volume mixture solution of $\mathrm{HClO}_{4}: \mathrm{C}_{2} \mathrm{H}_{5} \mathrm{OH}$ at $3^{\circ} \mathrm{C}$. Field emission scanning electron microscopy (FE-SEM, Hitachi S-4700) is used to characterize the surface morphology of the $\mathrm{Al}$ foil after the electropolishing process. The $\mathrm{Al}$ strips are removed and there are no obvious defects are found in FE-SEM images as shown in Fig. 2(a).

Subsequently, a two-step anodization process is carried out in a $0.3 \mathrm{M} \mathrm{H}_{2} \mathrm{C}_{2} \mathrm{O}_{4}$ solution. The temperature of the reactive solution is set to $3^{\circ} \mathrm{C}$. The duration of first anodization is $8 \mathrm{~h}$ at $40 \mathrm{~V}$ bias voltage, and the thickness of NP film is controlled by the anodization duration. A constant stirring process is maintained through the entire first anodization.

$\mathrm{A} \sim 80 \mu \mathrm{m} \mathrm{NP} \mathrm{Al}_{2} \mathrm{O}_{3}$ layer with a nonuniform layer on the top and a uniform layer on the bottom can be observed in cross-section FE-SEM, shown in Ref. [17]. Figure 2(b) displays the top view SEM image of the sample after the first anodization. It is relatively obvious that this formed $\mathrm{NP} \mathrm{Al}_{2} \mathrm{O}_{3}$ film is irregular. Inhomogeneity may result from the generation of heat on the surface of electrolyte during the first anodization. Moreover, at the bottom of the $\mathrm{NP} \mathrm{Al}_{2} \mathrm{O}_{3}$ layer, a compact dielectric oxide 
148 barrier layer is formed after the first anodization. The structure of the barrier layer can

149 be characterized by cross-section FE-SEM, shown in Fig. 3. The thickness of barrier 150 layer ranges from $30 \mathrm{~nm}$ to $45 \mathrm{~nm}$.

151 In order to improve the regularity of the NP nanoarray, the disordered $\mathrm{NP}^{-\mathrm{Al}_{2} \mathrm{O}_{3}}$

152 film is removed using wet chemical etching with a $0.2 \mathrm{M} \mathrm{CrO}_{3}$ and $0.4 \mathrm{M} \mathrm{H}_{3} \mathrm{PO}_{4}$

153 solution at $\sim 65^{\circ} \mathrm{C}$ for $\sim 6 \mathrm{~h}$. A highly periodic nano-concave structure on the $\mathrm{Al}$ substrate

154 is shown in Fig. 4. These pits serve as the template for the formation of the uniform NP

$155 \mathrm{Al}_{2} \mathrm{O}_{3}$ film during the second anodization [39].

156 The second anodization is carried out using the same apparatus and under the same 157 condition (temperature, concentration of solution, and bias voltage). Well-ordered

158 hexagonal pore arrays are obtained as shown in Fig. 2(c), demonstrating that the 159 irregular pore lattice after the first anodization does not adversely influence the 160 formation of $\mathrm{NP} \mathrm{Al}_{2} \mathrm{O}_{3}$ films during the second anodization. The pore diameter and 161 interpore distance can be estimated based on top-view FE-SEM images. The interpore 162 distance and pore diameter are $105 \pm 5 \mathrm{~nm}$ and $33 \pm 3 \mathrm{~nm}$, respectively.

163 Pulsed $\mathrm{THz}$ reflective imaging and $\mathrm{THz}$ scattering imaging are employed in this 164 study. A schematic diagram of the setup for reflective imaging, based on a TeraView 165 TPS Spectra 3000, is shown in Fig. 1. In scattering imaging, the detector is placed off 166 the specular direction. The generation of $\mathrm{THz}$ pulsed radiation is based on a 167 photoconductive switch. Quasi-single-cycle THz pulses with bandwidth $60 \mathrm{GHz}$ to 3 $168 \mathrm{THz}$ are generated in a biased GaAs antenna excited by an Er-doped fiber laser emitting 169 sub-100-fs 780-nm pulses at $100 \mathrm{MHz}$ repetition rate with average output power $>65$

$170 \mathrm{~mW}$. Coherent detection of the reflected $\mathrm{THz}$ radiation is performed in a similar 171 photoconductive-antenna circuit. By focusing the laser beam onto the photoconductive 172 gap of a biased semiconductor emitter and using a similar receiver, a current 
173 proportional to the $\mathrm{THz}$ electric field is measured. A delay line is used to change the

174 difference in the optical delay between the incoming $\mathrm{THz}$ pulse and the probe laser

175 pulse at the receiver. A bias is also applied across the emitter and receiver to generate

176 a time-gated output signal.

177 The $\mathrm{THz}$ measurements were carried out in an air-conditioned laboratory at $22^{\circ} \mathrm{C}$

178 with humidity $<48 \%$. Before the $\mathrm{THz}$ measurement, the reference pulse, i.e., the $\mathrm{THz}$

179 pulse produced by the apparatus, was recorded by setting a bare metal plate (an

180 excellent THz reflector) at the sample position. The sample was raster-scanned by a set

181 of motorized stages moving in the $x$ - and $y$-directions with step size $0.2 \mathrm{~mm}$. The

182 recorded reflected temporal signal at each pixel contains 4096 data points

183 (corresponding sampling period $T_{\mathrm{s}}$ is $0.0116 \mathrm{ps}$ ) and is averaged over 10 shots per pixel 184 to reduce the effect of noise.

\section{RESULT \& DISCUSSION}

\subsection{AFM CHARACTERIZATION}

AFM (Dimension Edge, Bruker) is used next to characterize the surface morphology of

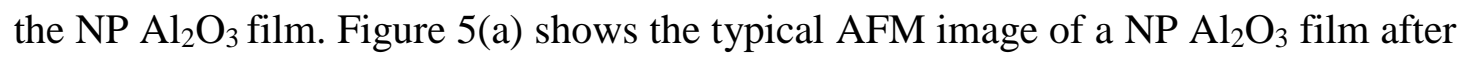
the second anodization. High regularity of closed packed hexagonal cells with circular nanopores are seen. The pore diameter, the interpore distance as well as the regularity

191 of the NP arrays can be calculated by analysis software through the line scan primary profiles of AFM shown in Fig. 5(b). The peaks and the valleys refer to walls and pores, respectively. The calculated interpore distance based on the interval between the peaks

194 or valley regions is $\sim 110 \mathrm{~nm}$, within the range estimated using FE-SEM image

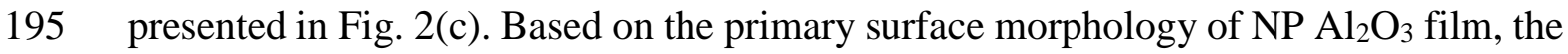
196 roughness profile can be obtained after applying a high-pass filter. The cutoff 
wavelength of the high-pass filter applied here is $0.039 \mu \mathrm{m}$, because the waviness profile obtained through applying low-pass filter with the same cutoff wavelength to

199 the primary surface profile, is comparable to the primary surface profile. Figure 5(c) is 200 the roughness profile along the red line marked in Fig. 5(a). The presence of the 201 nanoscale protrusions as well as the rugosity along the line lead to the distortion of the 202 unevenness of the surface. The closer to these irregular areas, the rougher the surface 203 would be. These nanoscale surface protrusions may result from the collapse of NP $204 \mathrm{Al}_{2} \mathrm{O}_{3}$ on the surface [19]. B-spline smoothing filter is utilized to extract the roughness 205 information from the line-scan roughness profile. Unlike Gaussian smoothing filter, 206 which has relatively obvious edge effect and large fluctuations [40], B-spline 207 smoothing filter can guarantee a better performance of the roughness evaluation and 208 has been adopted as a standard to evaluate the roughness [41]. Some stipulated 209 evaluation parameters, such as the roughness average $\left(R_{a}\right)$, the root mean square 210 roughness $\left(R_{q}\right)$, and the average maximum height of the profile $\left(R_{z}\right)$, are estimated based 211 on AFM results, to $1.644 \mathrm{~nm}, 2.275 \mathrm{~nm}$, and $16.18 \mathrm{~nm}$, respectively.

\subsection{THz MEASUREMENTS}

213 Because AFM fails to easily provide comprehensive information on the $\mathrm{NP} \mathrm{Al}_{2} \mathrm{O}_{3}$ film 214 and is quite sensitive to the surface fluctuations, THz measurements are performed next 215 in a nondestructive fashion to characterize the samples after electropolishing, the first, 216 and the second anodization, with the reflected THz signals in Fig. 2(d)-(f). The signal 217 reflected from the electropolished Al substrate is shown in Fig. 2(d). It is essentially the 218 same as the reference signal as the $\mathrm{Al}$ substrate is highly reflective to $\mathrm{THz}$ radiation.

219 The reflected signals in Figs. 2(e) and (f) are more complex. A typical signal 220 reflected from the sample after the first anodization is shown in Fig. 2(e). Due to the 221 inhomogeneous surface of the $\mathrm{NP} \mathrm{Al}_{2} \mathrm{O}_{3}$ films in cross-sectional FE-SEM shown in Ref. 
222 [17], reflections occur from features of various heights within the frequency-dependent 223 spot size of the $\mathrm{THz}$ beam $(\sim 300 \mu \mathrm{m}$ at $1 \mathrm{THz})$, resulting in a complex reflected pulse.

224 Moreover, scattering (signal emitted in non-specular directions) is expected to be 225 important due to the roughness, as we see below. We next turn to samples following 226 the second anodization, for which the NP lattice is quite regular, and the surface 227 morphology is flat. In this case, scattering is expected to be relatively weak. Four 228 temporarily overlapped reflections of the incident reference signal (i.e., echoes) are 229 observed in Fig. 2(f). The first positive echo corresponds to the air/ $/ \mathrm{NP}^{-1} \mathrm{I}_{2} \mathrm{O}_{3}$ interface 230 and the second positive echo corresponds to the $\mathrm{NP}^{-1} \mathrm{O}_{2} / \mathrm{Al}$ interface. The third and 231 fourth echo are the multiple reflection signals as $\mathrm{THz}$ wave propagates in $\mathrm{NP} \mathrm{Al}_{2} \mathrm{O}_{3}$ 232 material, and the change of sign results from the phase shift as expected. The 233 observation of the first two distinct echoes indicates that the two interfaces are smooth 234 on the scale of the THz spot size and well defined. The time delay between these two 235 echoes and a knowledge of the film's refractive indices enable us to measure the film 236 thickness; this technique is known as time-of-flight tomography (TOFT).

237 As pointed out above, non-specular scattering is related to inhomogeneity. We 238 explore scattering by varying the scattering (detector) angle $\phi$ while fixing the 239 incidence (emitter) angle near normal incidence $\left(\sim 3^{\circ}\right)$. Corresponding C-scans of the $240 \mathrm{NP} \mathrm{Al}_{2} \mathrm{O}_{3}$ films after the first and second anodization process are shown in Figs. 6 and 2417 , where the contrast mechanism is the maximum amplitude of the scattered signal. The $242 \mathrm{NP} \mathrm{Al}_{2} \mathrm{O}_{3}$ film lies only within a 1-cm diameter disk on the substrate, as presented in 243 Fig. 8, while the remaining area is electropolished Al. Due to the beam divergence, to 244 ensure a signal dominated by scattering, we need to choose $\phi>10^{\circ}$. For $\phi>10^{\circ}$, the 245 strength of the scattered signal depends markedly on surface morphology. An 246 inhomogeneous region between $0.7 \mathrm{~cm}$ and $1.1 \mathrm{~cm}$ in the $x-$, and $0.4 \mathrm{~cm}$ and $0.7 \mathrm{~cm}$ in 
the $y$-direction after the first anodization step, and position $0.6 \mathrm{~cm}$ and $1.0 \mathrm{~cm}$ in the $x$ and $0.3 \mathrm{~cm}$ and $0.6 \mathrm{~cm}$ in the $y$-direction after the second anodization, is clearly seen in

249 Figs. 6 and 7. As $\phi$ increases further, the overall signal level falls significantly, as seen 250 in Fig. 9. The increasingly mottled appearance of the C-scans with increasing $\phi$ is due 251 to the decrease in the signal-to-noise ratio (SNR) as $\phi$ increases. When $\phi$ reaches $35^{\circ}$, 252 the C-scan is dominated by noise.

253 In order to investigate the surface morphology and nanopore arrangement of the 254 disordered area, other additional measurements are applied subsequently. Because of 255 the small view field of AFM, it is hard to provide a systematic investigation on the 256 microstructure of $\mathrm{NP} \mathrm{Al}_{2} \mathrm{O}_{3}$ film and significant contrast at one time. Therefore, top 257 view FE-SEM measurements are employed, and the corresponding result is displayed 258 in Fig. 10. Compared with the FE-SEM result for the well-ordered area presented in 259 Fig. 2(c), there is a slight change of density, pore diameter, as well as inter-distance. 260 These distortions contribute to the occurrence of non-specular scattering.

261 The origin of the disordered area is worthy of study. Based on previous works on $262 \mathrm{NP} \mathrm{Al}_{2} \mathrm{O}_{3}$ surface morphology, several tentative reasons are presented as follows. (1) 263 Transfer of substrate-related nanoscale defects into the NP $\mathrm{Al}_{2} \mathrm{O}_{3}$ disturbs the NP array 264 order[42]. (2) Because some pits and bumps persist on the Al substrate even after 265 electropolishing, seen in Fig. 2(a), those macro defects impact the formation of NP $266 \mathrm{Al}_{2} \mathrm{O}_{3}[43]$. (3) Because the degree of $\mathrm{NP}$ order is largely determined by a certain value 267 of anodizing potential, nonoptimal anodization parameters could lower the degree of 268 pore order [44]. (4) Due to the long etching process $(\sim 6 \mathrm{~h})$, etching during the first 269 anodization process may be nonuniform, perhaps also connected to defects in the 270 substrates as discussed above. Because of the complicated process of sample 271 preparation, there is no consensus on the details of the roles of the above mechanisms. 
272 Indeed, it is likely that the answer depends on various aspects of the materials and 273 processes employed.

274 The stratigraphy of the well-ordered $\mathrm{NP}^{-1} \mathrm{O}_{2} \mathrm{O}_{3}$ film can also be characterized based 275 on THz B-scans along a cross-section using TOFT. Such a B-scan in Fig. 11 is along $276 y=0.4 \mathrm{~mm}$ as shown in Fig. 7. The narrow bright band near optical delay $\sim 10 \mathrm{ps}$ 277 corresponds to the top air/ $\mathrm{NP} \mathrm{Al}_{2} \mathrm{O}_{3}$ interface. In addition, the $\mathrm{NP} \mathrm{Al}_{2} \mathrm{O}_{3} / \mathrm{Al}$ interface as 278 well as the multiple reflections at later delays can be identified clearly. It is noted that 279 the reflection from the $\mathrm{Al}$ substrate occurs later in the regions with the $\mathrm{NP} \mathrm{Al}_{2} \mathrm{O}_{3}$ film 280 than from where it is absent, which is expected due to the refractive index $n>1$ of the 281 film. Based on the optical delay $\Delta t$ between the $1^{\text {st }}$ and $2^{\text {nd }}$ echoes, and the refractive 282 index $n$ of $\mathrm{Al}_{2} \mathrm{O}_{3}$ within $\mathrm{THz}$ regime ignoring the air fill factors [45], which is $\sim 3$, the $283 \mathrm{Al}_{2} \mathrm{O}_{3}$ film thickness is $c \Delta t / 2 \mathrm{n} \sim 87 \mu \mathrm{m}$ with $c$ the speed of light. This is in good 284 agreement with destructive cross-sectional FE-SEM. More detailed discussions of 285 thickness characterization of $\mathrm{NP} \mathrm{Al}_{2} \mathrm{O}_{3}$ film by sparse deconvolution can be found in 286 Ref. [17].

287 We also note that birefringence can be observed because of the anisotropy $\mathrm{NP}^{-\mathrm{Al}_{2} \mathrm{O}_{3}}$ 288 film [46]. The birefringence is relatively small and does not appreciably affect the film 289 thickness determination. We refer the reader to Refs. [17,47] for details on 290 birefringence discussion for $\mathrm{NP} \mathrm{Al}_{2} \mathrm{O}_{3}$ film.

\section{4. CONCLUSION}

292 In this study, two anodization processes were used to form $\mathrm{NP}^{-} l_{2} \mathrm{O}_{3}$ films on $\mathrm{Al}$ 293 substrate. The NP diameter, depth, and lattice constant of $\mathrm{NP} \mathrm{Al}_{2} \mathrm{O}_{3}$ films are measured 294 by FE-SEM and AFM. A poorly ordered $\mathrm{NP} \mathrm{Al}_{2} \mathrm{O}_{3}$ film is formed after the first 295 anodization, exhibiting rough surface morphology. A smooth and ordered NP array is 
296 formed after the second anodization. An area with rough surface morphology is

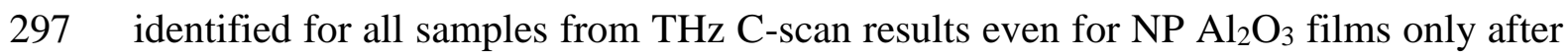
298 the first anodization process. The THz scattering results are corroborated by FE-SEM 299 measurements. The thickness of $\mathrm{NP}^{-} \mathrm{Al}_{2} \mathrm{O}_{3}$ films calculated based on $\mathrm{THz}$ results is in 300 excellent agreement with destructive cross-sectional FE-SEM measurement. To 301 conclude, THz reflective imaging and scattering imaging are useful tools to characterize 302 the homogeneity $\mathrm{NP} \mathrm{Al}_{2} \mathrm{O}_{3}$ films and other nanoscale materials with thickness in dozens 303 of $\mu \mathrm{m}$ and above. The approach is noncontact, nonionizing, and nondestructive; itcan

304 serve as a complementary technique that covers a large area and can be used to identify 305 regions that would warrant further examination with high-resolution techniques. 306 Specifically, for the $\mathrm{NP}^{-} l_{2} \mathrm{O}_{3}$ films, competing approaches, such as optical microscopy, 307 AFM, and FE-SEM either lack the requisite resolution or may result in damage to the 308 films.

\section{ACKNOWLEDGEMENTS}

We gratefully acknowledge the support of ArcelorMittal, Conseil Régional Grand Est, and CPER SusChemProc. 


\section{REFERENCE}

[1]. G. Schmid, "Materials in nanoporous alumina," J. Mater. Chem. A, 12(5): 1231-8, 2002. 10.1039/B110753B.

[2]. B.N. Kim, K. Hiraga, K. Morita, H. Yoschida, T. Miyazaki, and Y. Kagawa, "Microstructure and optical properties of transparent alumina," Acta Mater., 57(5):1319-26, 2009. https://doi.org/10.1016/j.actamat.2008.11.010.

[3]. L.F. Marsal, L. Vojkuvka, P. Formentin, J. Pallarés, and J. Ferré -Borrull, "Fabrication and optical characterization of nanoporous alumina films annealed at different temperatures," Opt. Mater., 31(6): 860-4, 2009. https://doi.org/10.1016/j.optmat.2008.09.008.

[4]. G. Mestres, M. Espanol, W. Xia, M. Tenje, and M. Ott, "Evaluation of biocompatibility and release of reactive oxygen species of aluminum oxide-coated materials," ACS Omega, 1(4): 2016. https://doi.org/10.1021/acsomega.6b00198.

[5]. M. Alsawat, T. Altalhi, T. Kumeria, A. Santos, and D. Losic, "Carbon nanotubenanoporous anodic alumina composite membranes with controllable inner diameters and surface chemistry: Influence on molecular transport and chemical selectivity," Carbon, 93: 681-92, 2015. https://doi.org/10.1016/j.carbon.2015.05.090.

[6]. M. Abd Elgadir, M.S. Uddin, S. Ferdosh, A. Adam, A.J. Chowdhury, and M.Z. Sarker, "Impact of chitosan composites and chitosan nanoparticle composites on various drug delivery system: A review," J. Food Drug Anal., 23(4): 619-29, 2015. https://doi.org/10.1016/j.jfda.2014.10.008.

[7]. D. Losic, and S. Simovic, "Self-ordered nanoporous and nanotube platforms for drug delivery applications," Expert Opin. Drug Deliv., 6(12): 1363-81, 2009. https://doi.org/10.1517/17425240903300857.

[8]. A. Santos, T. Kumeria, and D. Losic, "Nanoporous anodic aluminum oxide for chemical sensing and biosensor," Trac-Trend Anal. Chem. 1(44): 25-38, 2013. https://doi.org/10.1016/j.trac.2012.11.007.

[9]. B.T. Nguyen, A.E. Peh, C.Y. Chee, K. Fink, V.T. Chow, M.M. Ng, and C.S. Toh, "Electrochemical impedance spectroscopy characterization of nanoporous alumina dengue virus biosensor," Bioelectrochemistry, 88. 15-21, 2012. https://doi.org/10.1016/j.bioelechem.2012.04.006.

[10].P.S. Cheow, E.Z. Ting, M.Q. Tan, and C.S. Toh, "Transport and separation of proteins across platinum-coated nanoporous alumina membranes," Electrochim. Acta, 53(14): 4669-73, 2008. https://doi.org/10.1016/j.electacta.2008.01.070.

[11].T. Kumeria, and A. Santos, "Nanoporous alumina membranes for chromatography and molecular transporting," In Nanoporous Alumina, pp. 293-318, Springer, Cham, 
2015.

[12].T. Yang, X. Wang, W. Liu, Y. Shi, and F. Yang, "Double-layer antireflection coating containing a nanoporous anodic aluminum oxide layer for GaAs solar cells," Opt. Express, 21(15): 18207-15, 2013. https://doi.org/10.1364/OE.21.018207.

[13]. W. Lee, "The anodization of aluminum for nanotechnology applications," J. Opt. Mater., 62(6):57-63, 2010. https://doi.org/10.1007/s11837-010-0088-5.

[14].WJ. Stepniowski, D. Zasada, and Z. Bojar, "First step of anodization influences the final nanopore arrangement in anodized alumina," Surf. Coat. Technol, 206(6): 1416-22,2011. https://doi.org/10.1016/j.surfcoat.2011.09.004.

[15].H. Masuda, H. Yamada, M. Satoh, H. Asoh, M. Nakao, and T. Tamamura, "Highly ordered nanochannel-array architecture in anodic alumina," Appl. Phys. Lett, 71(19): 2770-2,1997. https://doi.org/10.1063/1.120128.

[16].A.C. GâIcă, E.S. Kooij, H. Wormeester, C. Salm, V. Leca, J.H. Rector, and B. Poelsema, "Structural and optical characterization of porous anodic aluminum oxide," J. Appl. Phys., 94(7): 4296-305, 2003. https://doi.org/10.1063/1.1604951.

[17].M. Zhai, A. Locquet, M. Jung, D. Woo, and D. Citrin, "Characterization of nanoporous $\mathrm{Al}_{2} \mathrm{O}_{3}$ films at terahertz frequencies," Opt. Lett. 45(14): 4092-5, 2020.https://doi.org/10.1364/OL.390129.

[18].M. Kubica, W. Skoneczny, and M. Bara, "Analysis of $\mathrm{Al}_{2} \mathrm{O}_{3}$ nanostructure using scanning microscopy," Scanning, 2018, 2018. https://doi.org/10.1155/2018/8459768.

[19].Y.Y. Zhu, G.Q. Ding, J.N. Ding, and N.Y. Yuan, "AFM, SEM, TEM studies on porous anodic alumina," Nanoscale Res. Lett, 5(4): 725, 2010. https://doi.org/10.1007/s11671-010-9538-9.

[20].Y. Sui, and J.M. Saniger, "Characterization of anodic porous alumina by AFM," Mater. Lett., 48(3-4): 127-36, 2001. https://doi.org/10.1016/S0167$\underline{577 X(00) 00292-5 .}$.

[21].K.S. Choudhari, P. Sudheendra, and N.K. Udayashankar, "Fabrication and hightemperature structural characterization study of porous anodic alumina membranes," J. Porous Mater., 19(6): 1053-62, 2012. 10.1007/s10934-012-9568-Z.

[22].K.S. Napolskii, I.V. Roslyakov, A.A. Eliseev, A.V. Petukhov, D.V. Byelov, N.A. Grigoryeva, W.G. Bouwman, A.V. Lukashin, K.O. Kvashnina, A.P. Chumakov, and S.V. Grigoriev, "Long-range ordering in anodic alumina films: a microradian X-ray diffraction study," J. Appl. Crystallogr., 43(3): 531-8, 2010. https://doi.org/10.1107/S0021889810009131.

[23].P.D. Pastuszak, A. Muc, and M. Barski, "Methods of Infrared Non-Destructive Techniques: Review and Experimental Studies," Key Eng. Mater., 542: 131-41, 2013. https://doi.org/10.4028/www.scientific.net/KEM.542.131. 
[24].M.M. Nazarov, A.P. Shkurinov, E.A. Kuleshov, and V.V. Tuchin, "Terahertz timedomain spectroscopy of biological tissues," IEEE. J. Quantum Electron., 38(7): 647, 2008.10.1070/QE2008v038n07ABEH013851.

[25].J. Dong, B. Kim, A. Locquet, P. McKeon, N. Declercq, and D.S. Citrin, "Nondestructive evaluation of forced delamination in glass fiber-reinforced composites by terahertz and ultrasonic waves," Compos. Part B- Eng. 79: 667-75, 2015. https://doi.org/10.1016/j.compositesb.2015.05.028.

[26].J. Dong, P. Pomarède, L. Chehami, A. Locquet, F. Meraghni, N.F. Declercq, D.S. Citrin, "Visualization of subsurface damage in woven carbon fiber-reinforced composites using polarization-sensitive terahertz imaging," NDT\&E Int, 99: 72-9, 2018. https://doi.org/10.1016/j.ndteint.2018.07.001.

[27].J.F. Federici, B. Schulkin, F. Huang, D. Gary, R. Barat, F. Oliveira, D. Zimdars, "THz imaging and sensing for security- explosives, weapons and drugs," Semicond. Sci. Technol, 20(7): S266, 2005. 10.1088/0268-1242/20/7/018.

[28].WH. Fan, A. Burnett, PC. Upadhya, J. Cunningham, EH. Linfield, AG. Davies, "Far-infrared spectroscopic characterization of explosives for security applications using broadband terahertz time-domain spectroscopy," Appl. Spectrosc., 61(6): 638-43, 2007. https://doi.org/10.1366/000370207781269701

[29]. J. Dong, A. Locquet, M. Melis, and D.S. Citrin, "Global mapping of stratigraphy of an old-master painting using sparsity-based terahertz reflectometry," Sci. Rep., 7(1): 1-12, 2017. https://doi.org/10.1038/s41598-017-15069-2.

[30].J. Dong, J.B. Jackson, M. Melis, D. Giovanacci, G.C. Walker, A. Locquet, J.W. Bowen, and D.S. Citrin, "Terahertz frequency-wavelet domain deconvolution for stratigraphic and subsurface investigation of art painting," Opt. Express, 24(23): 26972-85, 2016. https://doi.org/10.1364/OE.24.026972.

[31].K. Su, Y.C. Shen, and J.A. Zeitler, "Terahertz sensor for non-contact thickness and quality measurement of automobile paints of varying complexity," IEEE Trans. THz. Sci. Technol., 4(4): 432-9, 2014. 10.1109/TTHZ.2014.2325393.

[32].M. Zhai, A. Locquet, D.S. Citrin, "Pulsed imaging for thickness characterization of $\begin{array}{llll}\text { plastic sheets," } \quad \text { NDT\&E } & 2020 .\end{array}$ https://doi.org/10.1016/j.ndteint.2020.102338.

[33].S. Krishnamurthy, M.T. Reiten, S.A.Harmon, and R.A. Cheville, "Characterization of thin polymer using terahertz time-domain interferometry," Appl. Phys. Lett., 79(6): 875-7, 2001. https://doi.org/10.1063/1.1389823.

[34].M. Zhai, A. Locquet, C. Roquelet, P. Alexandre, L. Dahéron, and D.S. Citrin, "Nondestructive measurement of mill-scale thickness on steel by terahertz time-offlight tomography," Surf. Coat. Technol, 393, 125765, 2020. https://doi.org/10.1016/j.surfcoat.2020.125765. 
[35].J. Dong, A. Locquet, and D.S. Citrin, "Terahertz quantitative nondestructive evaluation of failure modes in polymer-coated steel," IEEE J. Sel. Top. Quantum Electron., 23(4): 1-7, 2016. 10.1109/JSTQE.2016.2611592.

[36].P. Dean, A. Valavanis, J. Keeley, K. Bertling, YL. Lim, R. Alhathlool, AD. Burnett, LH. Li, SP. Khanna, D. Indjin, T. Taimre, "Terahertz imaging using quantum cascade lasers - a review of systems and applications," J. Phys. D Appl. Phys., 47(37): 374008, 2014. https://doi.org/10.1088/0022-3727/47/37/374008.

[37]. J. Pearce, DM. Mittleman, "Propagation of single-cycle terahertz pulses in random media," Opt. Lett., 26(24): 2002-4, 2001. https://doi.org/10.1364/OL.26.002002.

[38].M. Jung, S.I. Mho, and H.L. Park, "Long-range-ordered CdTe/GaAs nanodot arrays grown as replicas of nanoporous alumina masks," Appl. Phys. Lett.,88(13): 133121, 2006. https://doi.org/10.1063/1.2191424.

[39].M.S. Ilango, A. Mutalikdesai, and S.K. Ramasesha, "Anodization of Aluminum using a fast two-step process," J. Chem. Sci., 128(1): 153-8, 2016. https://doi.org/10.1007/s12039-015-1006-8.

[40]. Y. Kondo, M. Numada, H. Koshimizu, K. Kamiya, and I. Yoshida, "Low-pass filter without the end effect for estimating transmission characteristics-Simultaneous attaining of the end effect problem and guarantee of the transmission characteristics," Precis. Eng., 48, 243-53, 2017. https://doi.org/10.1016/j.precisioneng.2016.12.007.

[41].ISO/TS 16610-22, "Geometrical product specifications (GPS)-Filtration-part 22: Linear profile filters: Spline filters," 2003.

[42].J.M. Runge, The metallurgy of anodizing aluminum, Cham: Springer International Publishing, 2018.

[43].M. Bara, M. Niedzwiddz, and W. Skoneczny, "Influence of anodizing parameters on surface morphology and surface-free energy of $\mathrm{Al}_{2} \mathrm{O}_{3}$ layers produced on $\mathrm{EN}$ AW-5251 alloy," Materials, 12(5): 695, 2019. https://doi.org/10.3390/ma12050695.

[44]. S.Z. Chu, K. Wada, S. Inoue, M. Isogai, and A. Yasumori, "Fabrication of ideally ordered nanoporous alumina films and integrated alumina nanotube arrays by highfield anodization," Adv. Mater., 17(17): 2115-9, 2005. https://doi.org/10.1002/adma.200500401.

[45].Y. Kim, M. Yi, B.G. Kim, and J. Ahn, "Investigation of THz birefringence measurement and characterization in $\mathrm{Al}_{2} \mathrm{O}_{3}$ and $\mathrm{LiNbO}_{3}$," Appl. Opt, 50(18): 290610, 2011. https://doi.org/10.1364/AO.50.002906.

[46].L. Zaraska, E. Wierzbicka, E. Kurowska-Tabor, and GD. Sulka, Nanoporous Alumina: Fabrication, Structure, Properties, Applications, Ed D. Losic and A. Santos, Berlin: Springer, 2015.

[47].A.A. Lutich, M.B. Danailov, S. Volchek, V.A. Yakovtseva, V.A. Sokol, and S.V. Gaponenko, "Birefringence of nanoporous alumina: dependence on structure 
parameters," Appl. Phys. B, 84(1-2): 327-31, 2006. https://doi.org/10.1007/s00340$\underline{006-2262-6 .}$ 


\section{FIGURE CAPTIONS}

Fig. 1. Schematic diagram of $\mathrm{THz}$ reflective imaging experiment.

Fig. 2. FE-SEM showing surface morphology after (a) electro-polishing, (b) first anodization, and (c) second anodization. Corresponding reflected $\mathrm{THz}$ signals are presented in (d)-(f).

Fig. 3. FE-SEM image of a barrier layer of $\mathrm{NP} \mathrm{Al}_{2} \mathrm{O}_{3}$ film on $\mathrm{Al}$ substrate.

Fig. 4. Top-view FE-SEM for sample after etching following the first anodization process.

Fig. 5. (a) $\mathrm{AFM}$ image of $\mathrm{NP} \mathrm{Al}_{2} \mathrm{O}_{3}$ film on $\mathrm{Al}$ substrate after the second anodization process; (b) the surface primary profile, and (c) roughness profile along the red line in Fig. 5(a).

Fig. 6. C-scans of sample after the first anodization process for various reflection angles with the polarization angle $\sim 0^{\circ}$ and incidence angle fixed (at $\sim 3^{\circ}$, i.e., near normal incidence). The contrast mechanism applied here is the maximum amplitude of the scattered signal.

Fig. 7. C-scans of sample after the second anodization process for various reflection angles with the polarization angle $\sim 0^{\circ}$ and incidence angle fixed (at $\sim 3^{\circ}$, i.e., near normal incidence). The contrast mechanism applied here is the maximum amplitude of the scattered signal. The horizontal line at $\mathrm{Y}=0.4 \mathrm{~cm}$, marked "Cross-section", is in reference to the B-scan in Fig. 11.

Fig. 8. Real image of the Al foil after the second anodization process. One 1-cm diameter disk region of $\mathrm{NP} \mathrm{Al}_{2} \mathrm{O}_{3}$ is found on $\mathrm{Al}$ substrate. 
Fig. 9. Maximum amplitude of reflected $\mathrm{THz}$ signal from sample after second anodization at different positions $(x, y)$ as a function of scattering angle $\phi$.

Fig. 10. FE-SEM image at disordered area.

Fig. 11. B-scan based on the raw data with the cross-section $Y=0.4 \mathrm{~cm}$. Inset shows origin of echoes in reflected THz signal: $1^{\text {st }}$ air $/ \mathrm{NP} \mathrm{Al}_{2} \mathrm{O}_{3}, 2^{\text {nd }} \mathrm{NP} \mathrm{Al}_{2} \mathrm{O}_{3} / \mathrm{Al}$, and $3^{\text {rd }}$ and $4^{\text {th }}$ multiple reflections. 


\section{FIGURES}

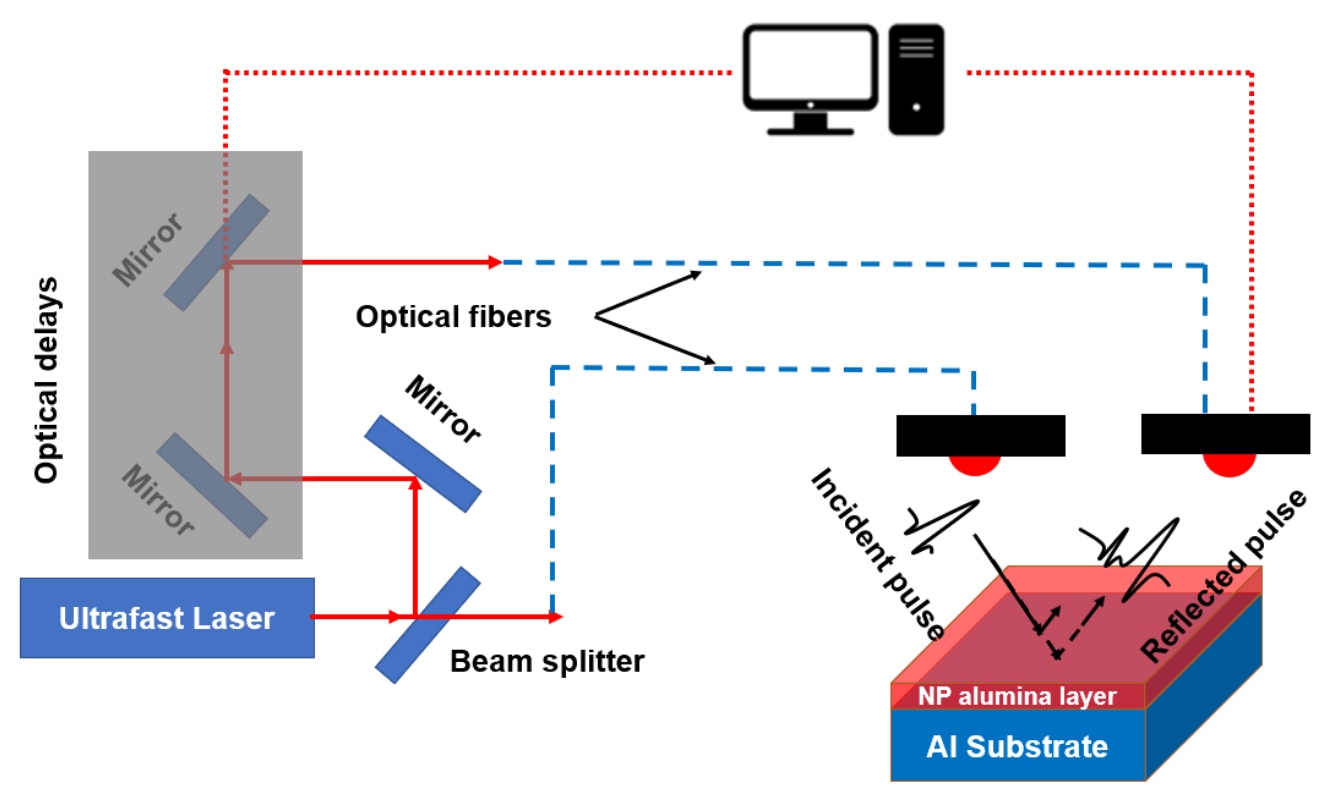

(1) 

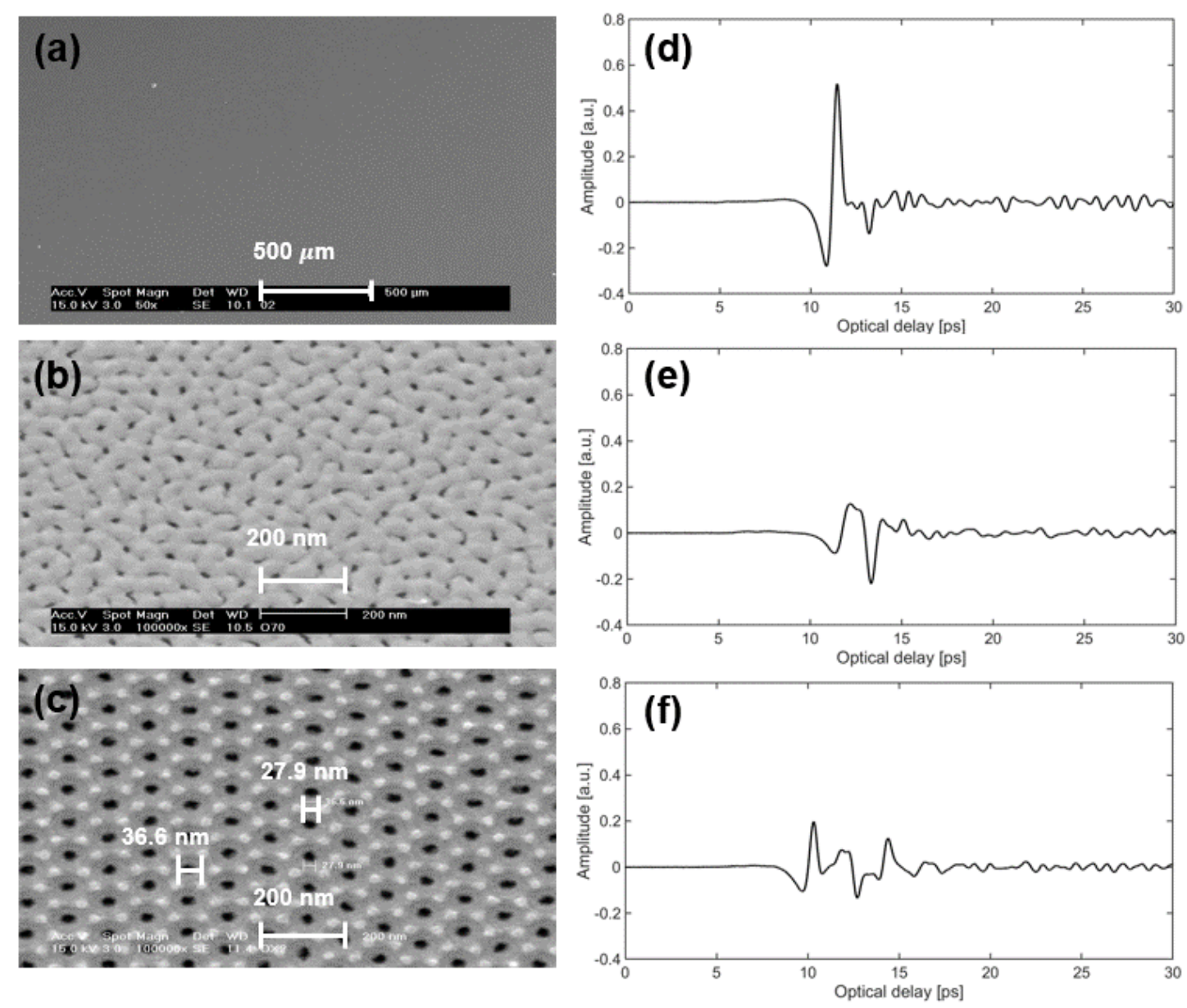

(2)

(3) 


\section{$\mathrm{NP} \mathrm{Al}_{2} \mathrm{O}_{3}$ layer}

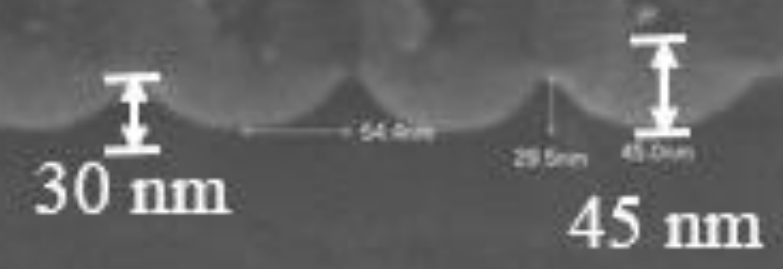

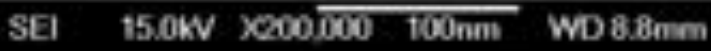


Hexagon shape

(4) 

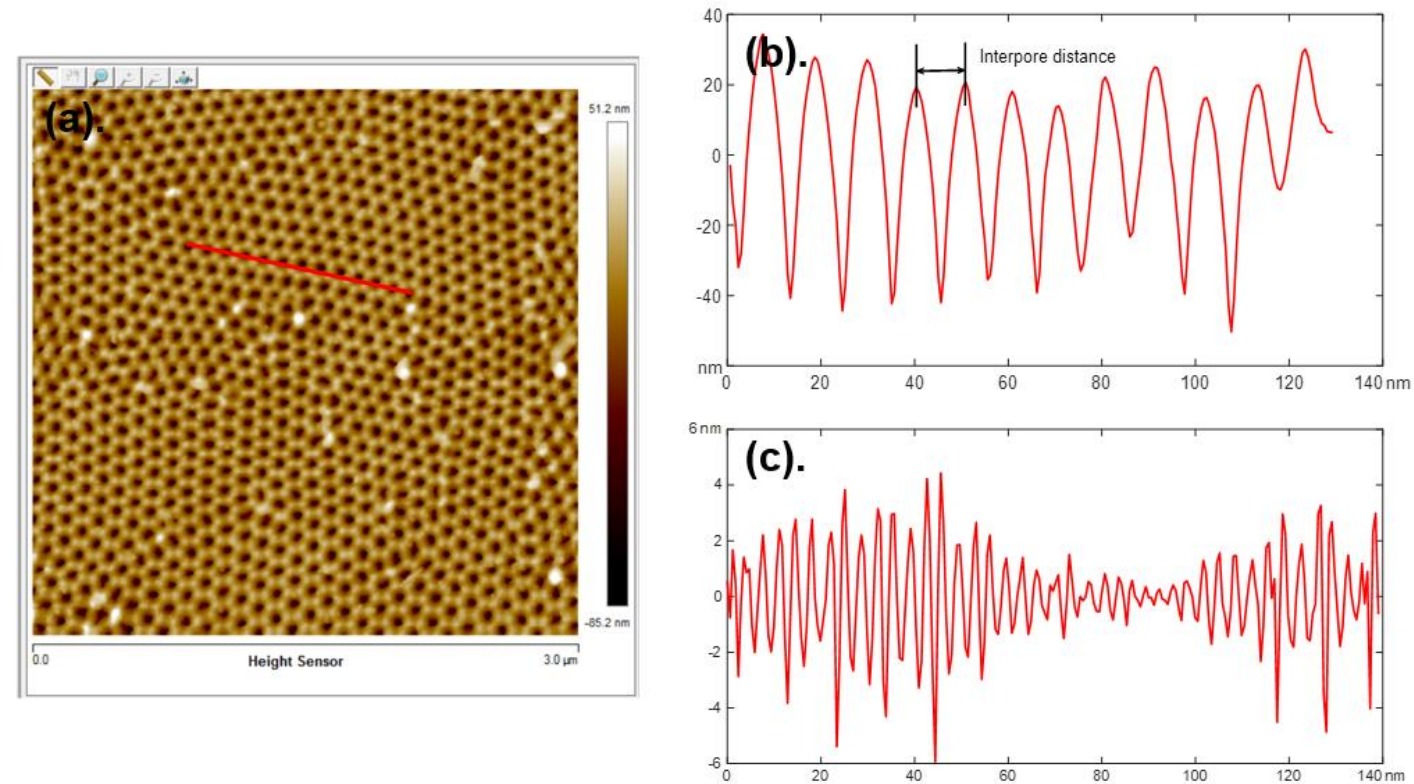

(5) 

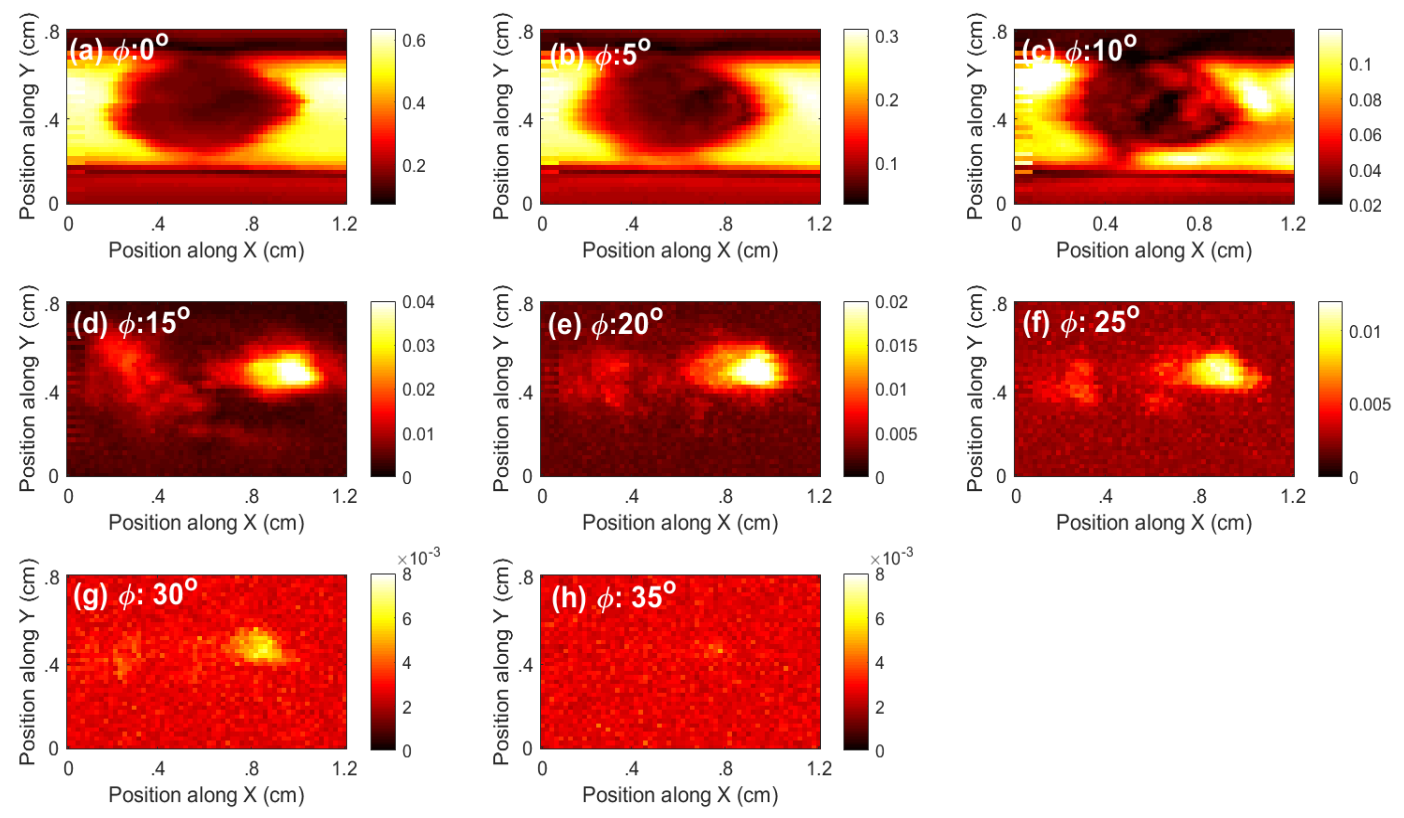

(6) 

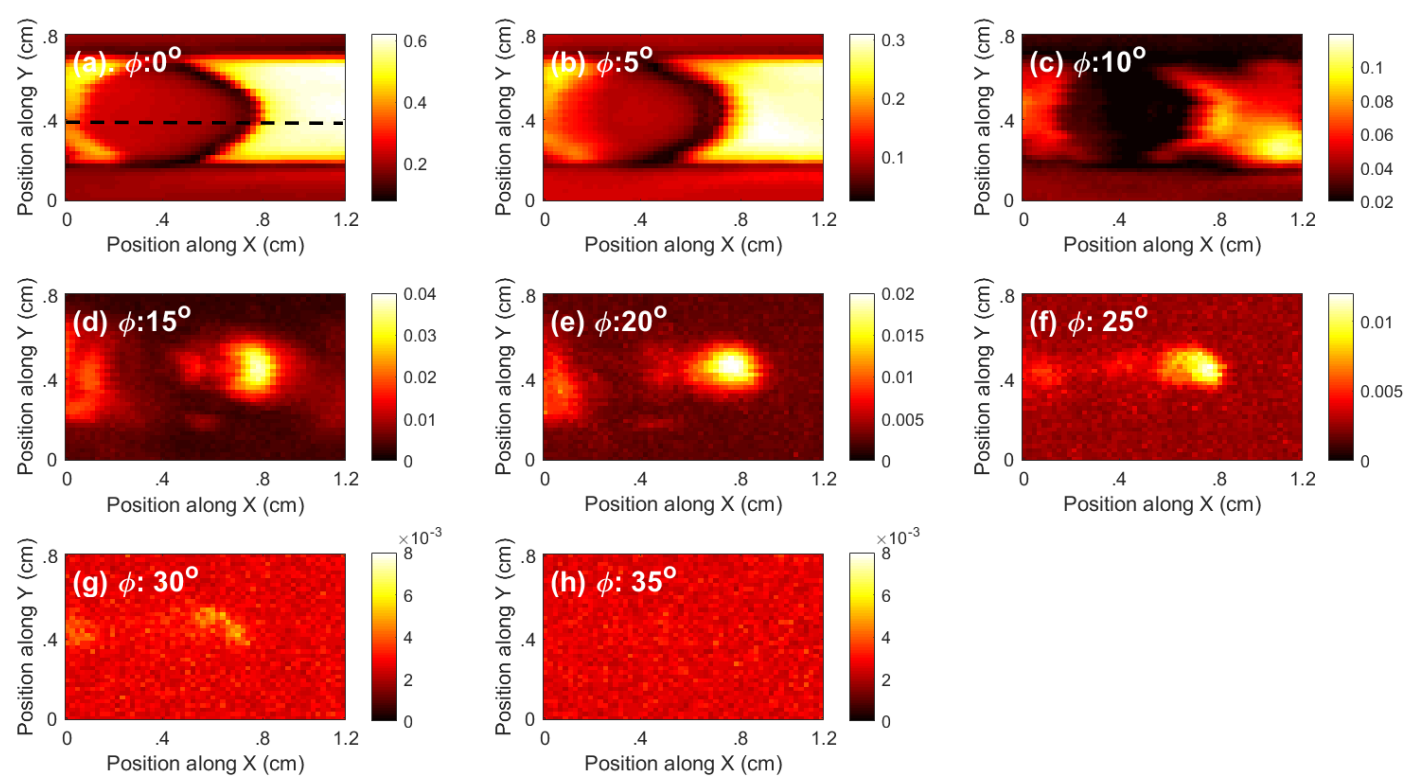

(7) 


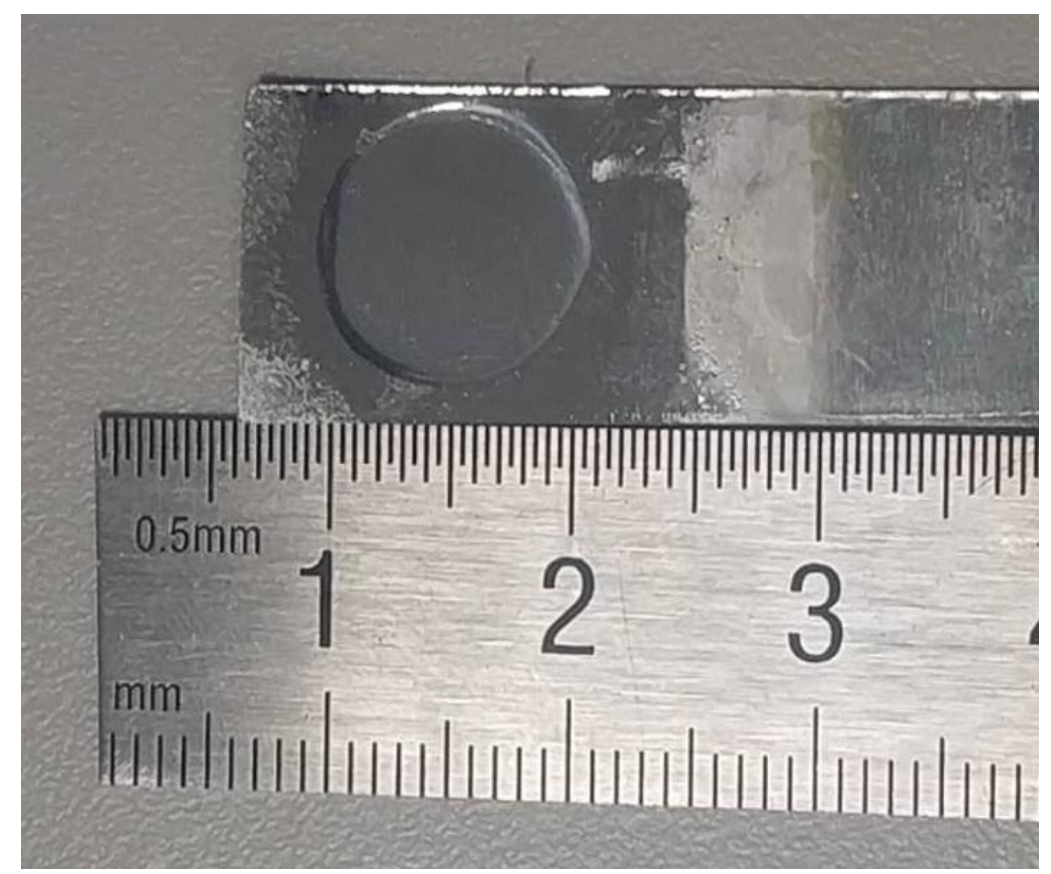

(8) 


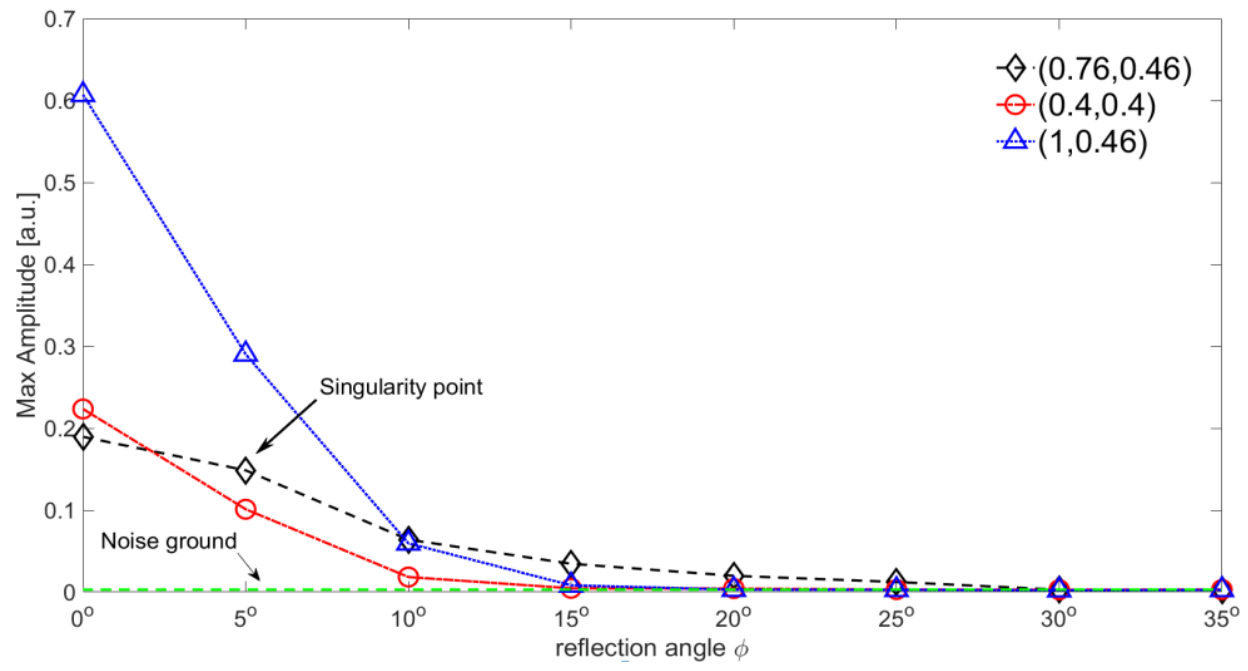

(9) 


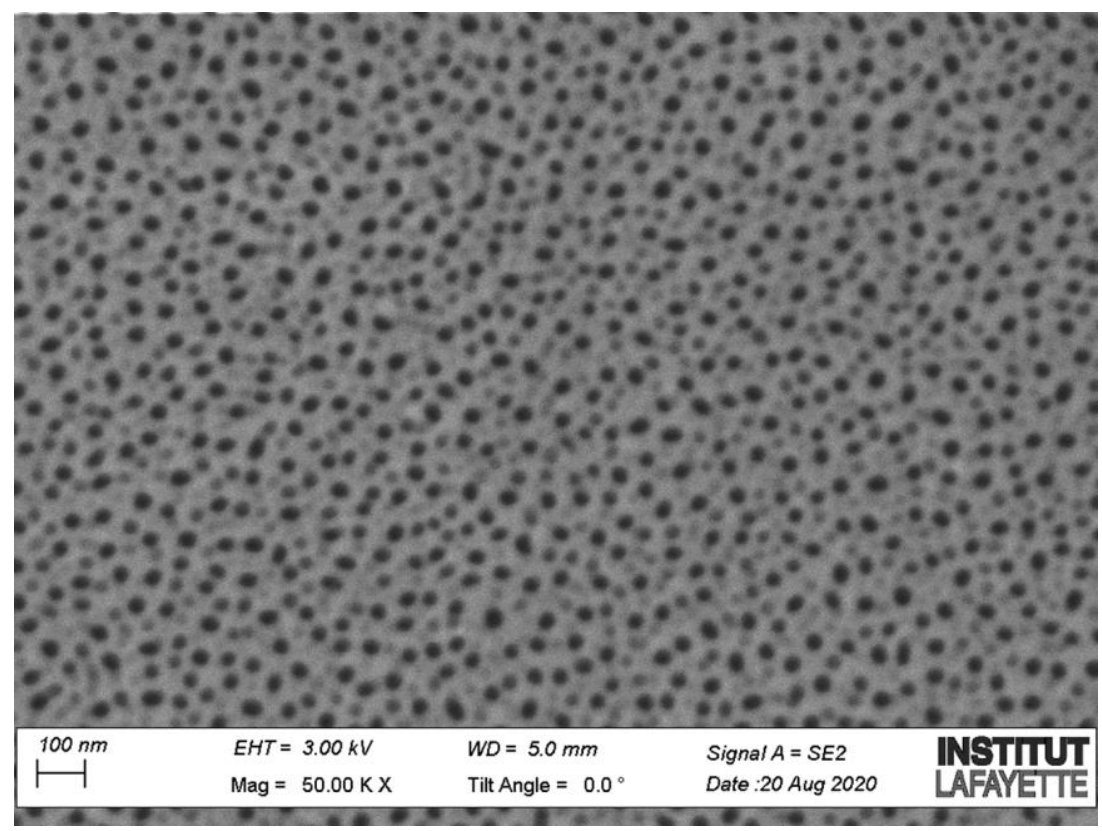

(10) 


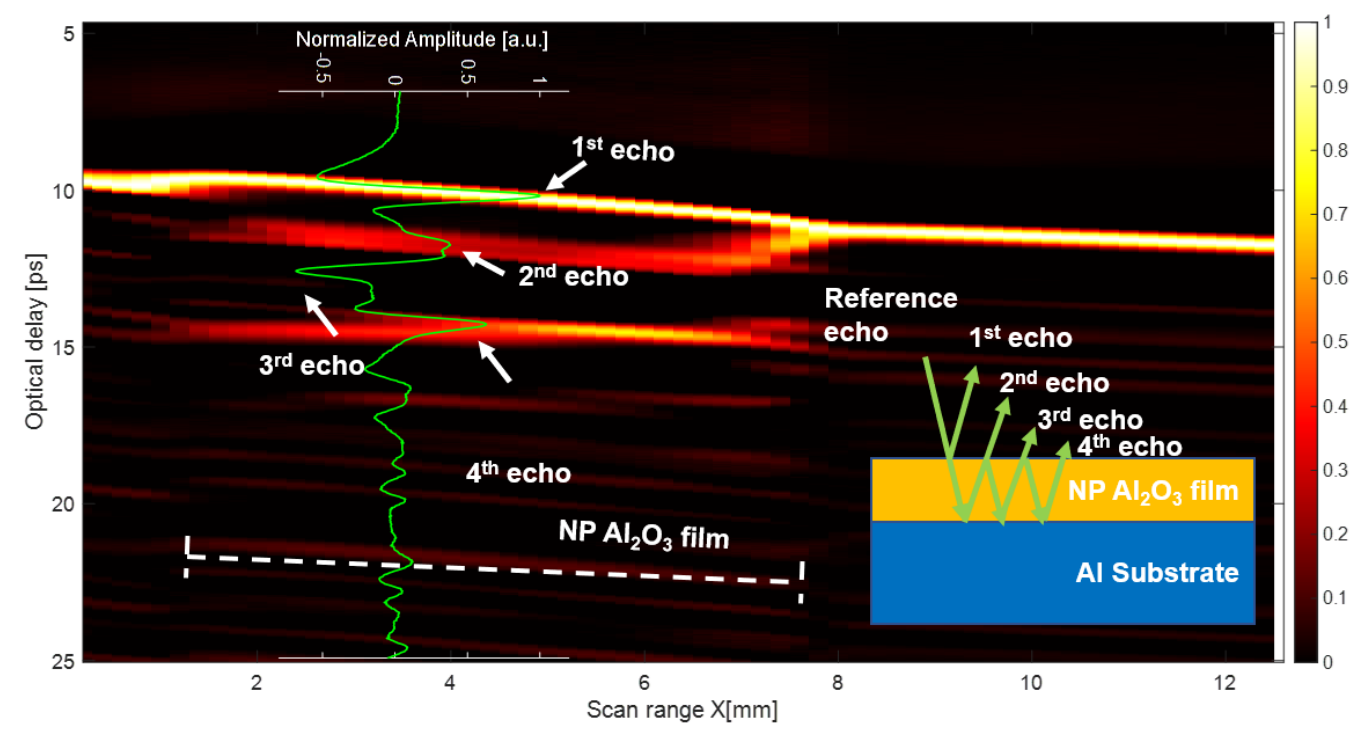

(11) 